\title{
Porous gold nanoparticles for attenuating infectivity of influenza A virus
}

\author{
Jinyoung Kim', Minjoo Yeom², Taeksu Lee ${ }^{3}$, Hyun-Ouk Kim², Woonsung Na , Aram Kang², Jong-Woo Lim', \\ Geunseon Park', Chaewon Park', Daesub Song ${ }^{2^{*}}$ and Seungjoo Haam ${ }^{1 *}$ (D)
}

\begin{abstract}
Background: Influenza viruses (IVs) have become increasingly resistant to antiviral drugs that target neuraminidase and matrix protein 2 due to gene mutations that alter their drug-binding target protein regions. Consequently, almost all recent IV pandemics have exhibited resistance to commercial antiviral vaccines. To overcome this challenge, an antiviral target is needed that is effective regardless of genetic mutations.
\end{abstract}

Main body: In particular, hemagglutinin (HA), a highly conserved surface protein across many IV strains, could be an effective antiviral target as it mediates binding of IVs with host cell receptors, which is crucial for membrane fusion. HA has 6 disulfide bonds that can easily bind with the surfaces of gold nanoparticles. Herein, we fabricated porous gold nanoparticles (PoGNPs) via a surfactant-free emulsion method that exhibited strong affinity for disulfide bonds due to gold-thiol interactions, and provided extensive surface area for these interactions. A remarkable decrease in viral infectivity was demonstrated by increased cell viability results after exposing MDCK cells to various IV strains (H1N1, H3N2, and H9N2) treated with PoGNP. Most of all, the viability of MDCK cells infected with all IV strains increased to 96.8\% after PoGNP treatment of the viruses compared to $33.9 \%$ cell viability with non-treated viruses. Intracellular viral RNA quantification by real-time RT-PCR also confirmed that PoGNP successfully inhibited viral membrane fusion by blocking the viral entry process through conformational deformation of HA.

Conclusion: We believe that the technique described herein can be further developed for PoGNP-utilized antiviral protection as well as metal nanoparticle-based therapy to treat viral infection. Additionally, facile detection of IAV can be achieved by developing PoGNP as a multiplatform for detection of the virus.

Keywords: Virus inactivation, Influenza A virus, Porous gold nanoparticle, Membrane fusion, Disulfide bond

\section{Introduction}

Acute respiratory diseases comprise over $75 \%$ of overall infectious disease occurrences in developed countries, of which $80 \%$ are caused by viruses [1]. Above all, the influenza virus (IV) is recognized as a serious public health concern with 200,000 hospitalizations and

\footnotetext{
*Correspondence: sds1@korea.ac.kr; haam@yonsei.ac.kr

1 Department of Chemical and Biomolecular Engineering, Yonsei University, Yonsei-ro 50, Seoul 120-749, Republic of Korea

2 Department of Pharmacy, Korea University College of Pharmacy, Sejong-ro 2511, Sejong 30019, Republic of Korea

Full list of author information is available at the end of the article
}

36,000 deaths annually in the United States alone [2]. To date, conventional commercialized antiviral agents for IV have been developed to control IV pandemics by blocking two different targets: matrix protein 2 (M2) ion channel and neuraminidase (NA) [3]. Transportation of $\mathrm{H}^{+}$ions across the transmembrane is blocked by the M2 ion channel inhibitor, which results in incomplete viral uncoating and prevents viral replication. The NA inhibitor interrupts the hydrolysis of terminal sialic acid residues on new IV, thus preventing the release of viruses from the infected host cell. Promotion of IV infection is interrupted with these inhibitors. However, the U.S. Centers for Disease Control (CDC) announced that over 
99\% of IV strains H3N2 and H1N1 present resistance to M2 ion channel inhibitors, including amantadine and rimantadine [4]. Furthermore, recent influenza strains, including those responsible for the pandemic outbreaks in 2009, showed enormously high resistance to the commercialized NA inhibitor, Tamiflu (oseltamivir) [5, 6]. Mutation of viral surface proteins has triggered incremental IV resistance to conventional drug treatments by transforming the drug binding site in its protein, hence increasing viral infectivity and mortality [7-9].

Hemagglutinin (HA), one of the viral surface proteins deeply involved in membrane fusion with the host cell, has been investigated as another potentially effective antiviral strategy. During the fusion process, disulfide bonds linking the two different parts of HA cleave to unfold the HA molecule and the fusion peptide hidden within causes membrane fusion to spread viral RNA to the host cell [10-12]. Disulfide bonds have a crucial role in the membrane fusion process as previously described [13-15], thus we focused on HA disulfide bonds as an antiviral target herein.

Meanwhile, inorganic metals such as gold and silver have been investigated for their ability to neutralize HA activity by cleaving HA disulfide bonds using their strong affinity for gold and silver. Especially, it has been reported that the silver-thiol interaction between HA disulfide bonds and silver nanoparticles (AgNPs) could inhibit IV infection by cleaving disulfide bonds [16-18]. Therefore, various modifications of noble metallic nanoparticles have been tested to mitigate viral infection, i.e., tannic acid-modified silver nanoparticle [19], silver nanoparticle/chitosan composite [20], curcumin-modified silver nanoparticle [21], PVP-coated silver nanoparticle $[22,23]$ multivalent gold nanoparticles [24-27] and gallic acid-functionalized gold nanoparticle [28]. These noble metal-based nanoparticles suppressed viral infection by blocking viral entry to the host cell.

Here, for an improved antiviral treatment agent using metallic nanoparticles, we introduced the porous gold nanoparticle (PoGNP) for cleaving disulfide bonds. PoGNPs permit a facile fabrication process that does not require additional heat or surfactant, while Ag-based nanoparticles should be modified with a capping agent for stabilization under in vitro conditions and to reduce their cytotoxicity. In addition, PoGNPs possess extensive surface area due to their unique nanobundled structure $[29,30]$. Moreover, PoGNPs are expected to have high affinity for disulfide bonds due to gold-disulfide bond formation and their extensive surface area can effectively inactivate the IV by cleaving disulfide bonds, which blocks membrane fusion and viral entry to the host cell.

In the present study, influenza A virus (IAV) was treated with PoGNP to show that PoGNP inactivates the virus (Scheme 1). To visualize this inactivation ability,

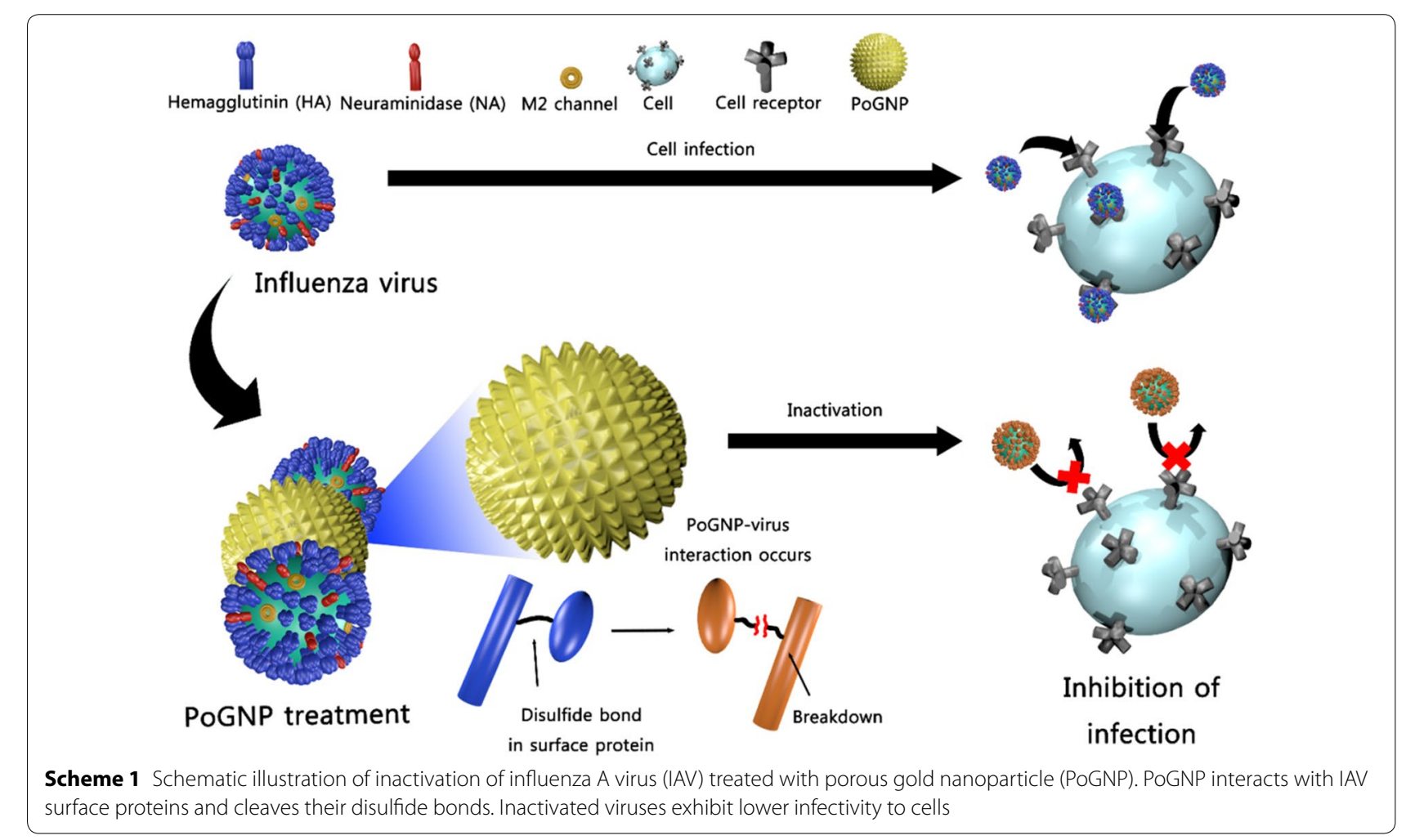


the amount of post-infection intracellular viral RNA was measured after nanoparticle treatment. In addition, various IV strains, including $\mathrm{H} 1 \mathrm{~N} 1, \mathrm{H} 3 \mathrm{~N} 2$, and $\mathrm{H} 9 \mathrm{~N} 2$, were analyzed to confirm the inhibition efficacy of PoGNP regardless of IAV mutation.

\section{Results and discussion}

Preparation and characterization of porous gold nanoparticle (PoGNP) and other metallic nanoparticles

In contrast to conventional gold nanoparticle synthesis, PoGNP was synthesized using the surfactant-free emulsion method. The $\mathrm{Au}^{3+}$ ion in $\mathrm{HAuCl}_{4}$ and anilinium ion $\left(\mathrm{C}_{6} \mathrm{H}_{5} \mathrm{NH}_{3}{ }^{+}\right)$formed the PANI-Au complex nanoparticle by reducing the $\mathrm{Au}^{3+}$ ion and oxidizing the anilinium ion to PANI through redox reaction [29]. After fabrication of the PANI-Au complex nanoparticle, PANI was selectively etched by NMP from the PANI-Au nanocomplex, shaping a mesoporous gold structure. Non-porous sGNP was synthesized via the seed-mediated growth method to compare whether nanoparticle morphology could affect inactivation of the virus. AgNP was also prepared as an antiviral control group as AgNP has been widely studied for its antiviral properties.

The morphology of the synthesized nanoparticles was observed by TEM and their average size was determined by dynamic light scattering (DLS) analysis. TEM images of synthesized PoGNP exhibited rough surfaces with $6 \mathrm{~nm}$-sized nanosphere bundles, composing $150 \mathrm{~nm}$ sized spherical structure (Fig. 1a) whereas sGNP and AgNP exhibited narrow monodispersed spherical structures with smooth surfaces (Fig. 1b, c, Additional file 1: Figure S1). Cumulative size of PoGNP, AgNP, and sGNP was 154.24 $\pm 37.05 \mathrm{~nm}$, $140.23 \pm 25.10 \mathrm{~nm}$ and $20.52 \pm 4.49 \mathrm{~nm}$, respectively
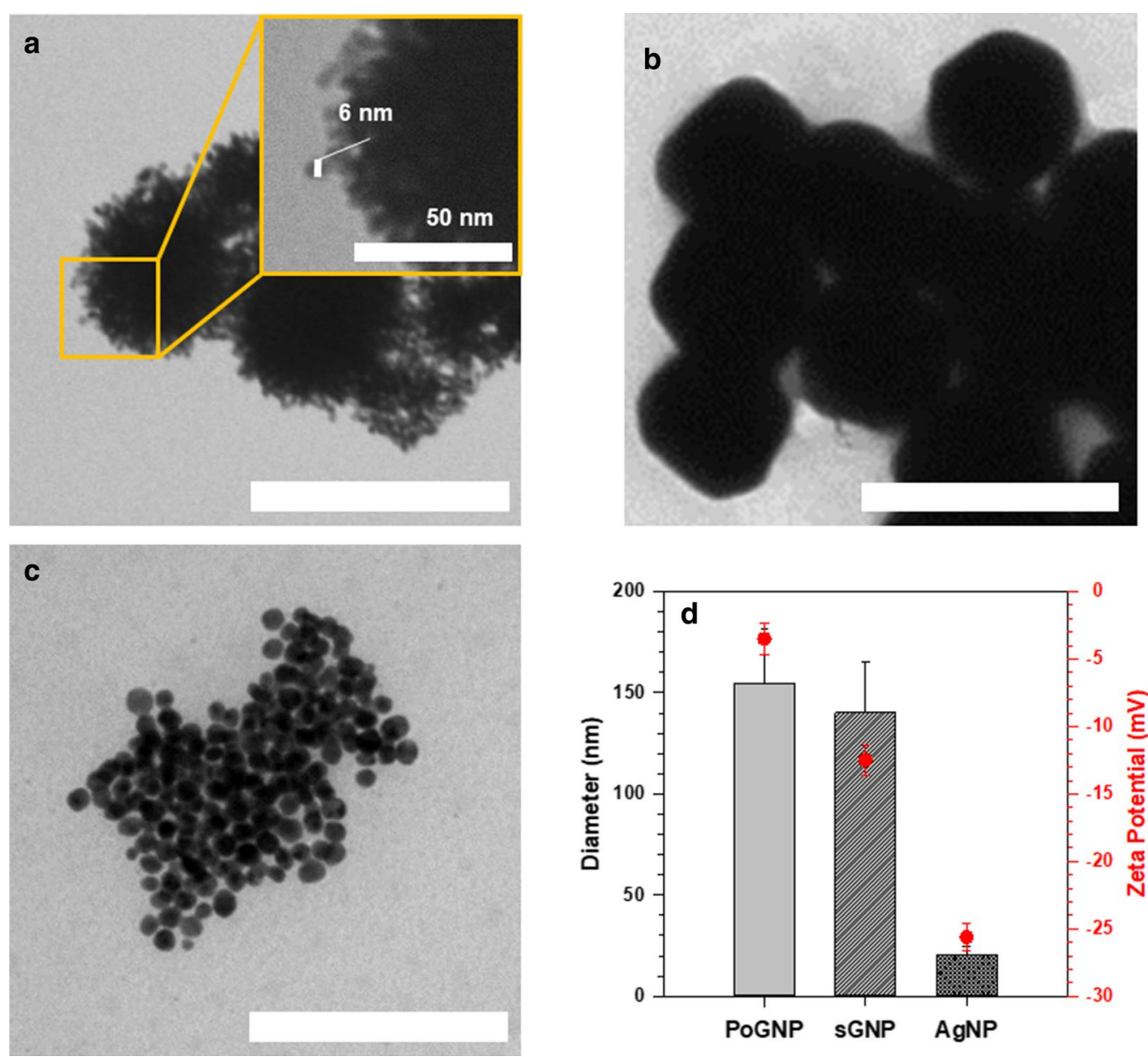

Fig. 1 a TEM image of fabricated PoGNP. Inlet image shows nanobundles on the surface of PoGNP. b sGNP, c AgNP, d Mean of cumulative size of nanoparticles determined by DLS analysis. Zeta potential of each nanoparticle was also obtained. The unlabeled scale bars represent 200 nm. PoGNP, porous gold nanoparticle; sGNP, spherical gold nanoparticle; AgNP, silver nanoparticle 
(Fig. 1d). Zeta potential of the formulated PoGNP was rather neutral charge $(-3.5133 \pm 1.1548 \mathrm{mV})$, compared to sGNP $(-12.4733 \pm 1.1243 \mathrm{mV})$ and AgNP $(-25.6167 \pm 0.9810 \mathrm{mV})$.

Moreover, the biocompatibility of the synthesized nanoparticles was evaluated by MDCK cell viability assay. MDCK cells in 96-well plates were exposed to various nanoparticle concentrations and cell viability was measured by the WST-1 assay, with the optical density being measured at $450 \mathrm{~nm}$. The measured cell viability after nanoparticle treatment was greater than 95\%, except for $0.2 \mathrm{mg} / \mathrm{mL}$ PoGNP and $0.1-0.2 \mathrm{mg} / \mathrm{mL}$ AgNP, which were observed to have $80 \%$ cell viability. The results of the nanoparticle cell viability assay implied that the infectivity of nanoparticle-treated viruses could be evaluated by MDCK cytotoxicity assay because the nanoparticles exhibited good biocompatibility with the MDCK cells (Additional file 1: Figure S2).

\section{Interaction between synthesized nanoparticle and influenza virus}

Interaction between the prepared nanoparticles and IAV HA was evaluated, as we hypothesized inactivation of IAV to be induced by cleaving disulfide bonds required for viral membrane fusion with the host cell. TEM analysis was first conducted for a simple confirmation of the interaction between the virus and the nanoparticles. IAV suspension was incubated with $2 \times 10^{-1} \mathrm{mg} / \mathrm{mL}$ of nanoparticles for $10 \mathrm{~min}$, and then the mixtures were prepared for TEM analysis. However, interaction was difficult to observe in the TEM images with larger NPs such as PoGNP and sGNP. On the other hand, AgNP agglomerated on the viral surface as expected, since the small size of AgNP facilitated migration (Fig. 2). Another technique was considered to prove the affinity between HA and the larger sGNPs. As the isolation of IAV requires ultracentrifugation over $20,000 \mathrm{~g}$ [31] or gradient centrifugation [32], we centrifuged the samples at $6000 \mathrm{~g}$ for $10 \mathrm{~min}$ to monitor whether H3N2 precipitated with the nanoparticles. We assumed that the nanoparticle-treated H3N2 virus would precipitate with the nanoparticles in contrast to the H3N2 virus sample alone. Definitively, the realtime cycle quantification $\left(\mathrm{C}_{\mathrm{q}}\right)$ value of PoGNP-treated $\mathrm{H} 3 \mathrm{~N} 2$ virus in redispersed precipitate solution was much lower than that in the supernatant, indicating that H3N2 virus could interact with PoGNP (Fig. 3). In addition, PoGNP attracted more $\mathrm{H} 3 \mathrm{~N} 2$ virus than sGNP at lower concentration according to the real-time $\mathrm{C}_{\mathrm{q}}$ values of precipitated samples, which indicated that PoGNP had much higher affinity for HA compared with sGNP. The difference in attraction resulted from their surface structure; the foam-shaped porous outer surface of PoGNP created more surface area for interaction with HA than the sGNP surface.

\section{Antiviral effect of PoGNP compared with other metallic nanoparticles}

To observe the antiviral effect of nanoparticles, H1N1 virus was exposed to each nanoparticle suspension for $10 \mathrm{~min}$ and 60 min prior to infection of the MDCK cells. The antiviral effect of the nanoparticles was determined by WST-1 cytotoxicity assay by observing the optical density of treated cells at $450 \mathrm{~nm}$. Compared with the other nanoparticles, PoGNP showed much higher antiviral activity on $\mathrm{H} 1 \mathrm{~N} 1$ virus, whereas AgNP showed only minor antiviral activity over $0.1 \mathrm{mg} / \mathrm{mL}$ AgNP. $0.2 \mathrm{mg} /$ mL PoGNP successfully inactivated H1N1 virus after exposure for $60 \mathrm{~min}$. In contrast, sGNP had no antiviral effect regardless of its concentration or exposure time (Fig. 4). Comparing PoGNP with sGNP, the difference in nanoparticle antiviral activity is the result of differences in their specific surface areas despite similar diameters; each nanoframe of PoGNP behaved as a single reactant for disulfide bonds that could interact with HA. AgNP was able to agglomerate on viral $\mathrm{HA}$ and had extensive specific surface area for interaction compared with sGNP due to its small size; however, PoGNP showed higher inactivation of the virus at $0.2 \mathrm{mg} / \mathrm{mL}$. PoGNP's superior virus inactivation ability compared with AgNP and sGNP is due to both its stability under saline conditions and its high affinity for HA. The antiviral effectiveness of AgNP is restricted because AgNP aggregated in the culture media at higher concentration and it should only be treated at concentrations lower than $0.1 \mathrm{mg} / \mathrm{mL}$ due to toxicity concerns. As observed by lower attraction of sGNP to viral HA in the binding efficiency test with centrifugation, sGNP exhibited lower antiviral activity, as expected. Indeed, the inactivation of $\mathrm{H} 1 \mathrm{~N} 1$ virus by sGNP was much lower than that of PoGNP, although sGNP also exhibited affinity for HA at higher concentration. This result endorsed the fact that inactivation of $\mathrm{H} 1 \mathrm{~N} 1$ virus was caused by the cleavage of disulfide bonds ensuing from the influence of metallic nanoparticles because the relatively flat surface of sGNP made contact with the disulfide bridge difficult in contrast to PoGNP's rough surface.

\section{Antiviral effect of PoGNP towards various influenza A virus subtypes}

To confirm the inactivation of PoGNP regardless of genetic mutation, 3 IAV strains $(\mathrm{H} 1 \mathrm{~N} 1, \mathrm{H} 3 \mathrm{~N} 2$, and H9N2) were treated with PoGNP (Fig. 5 and Additional file 1: Figure S3). According to the phylogenic tree of IAV, the selected virus strains had low sequence similarity, so they were considered representative of 

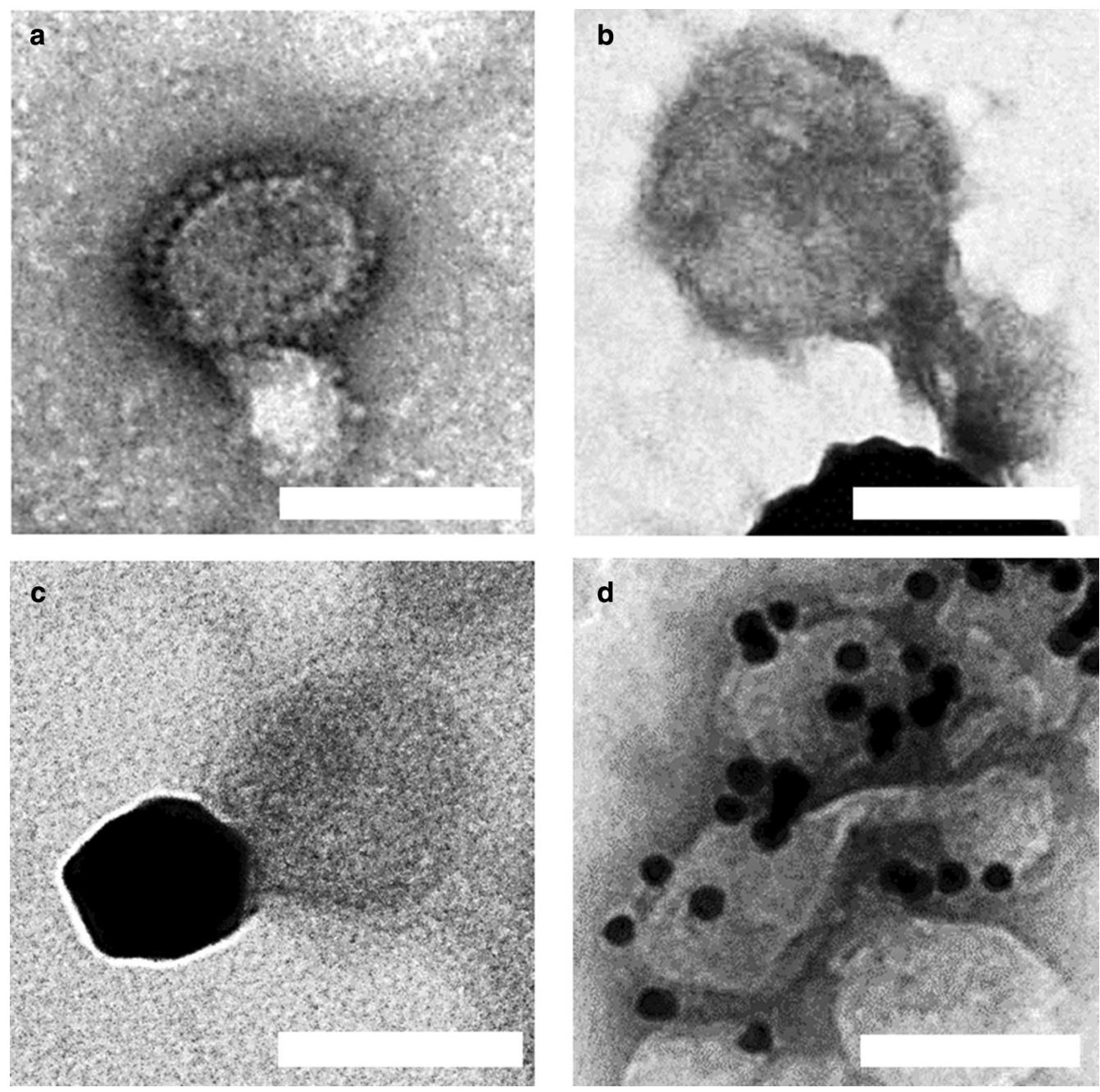

Fig. 2 a TEM image of IAV. b PoGNP-treated IAV. c sGNP-treated IAV. d AgNP-treated IAV. All scale bars represent $100 \mathrm{~nm}$. PoGNP, porous gold nanoparticle; sGNP spherical gold nanoparticle, AgNP silver nanoparticle

general viral treatment [33]. For the 10 min-treated sample, only $0.2 \mathrm{mg} / \mathrm{mL}$ PoGNP showed over $50 \%$ cell viability. Under $0.1 \mathrm{mg} / \mathrm{mL}$ PoGNP concentration, the treated virus was only slightly inactivated compared to the non-treated virus. After the $60 \mathrm{~min}$ treatment, the antiviral effect of treatment with $0.2 \mathrm{mg} / \mathrm{mL}$ PoGNP on $\mathrm{H} 1 \mathrm{~N} 1, \mathrm{H} 3 \mathrm{~N} 2$, and H9N2 increased to $74 \%, 76 \%$, and $56 \%$, respectively. $54 \%$ of MDCK cells survived H1N1 infection when treated with $0.1 \mathrm{mg} / \mathrm{mL}$ PoGNP for 60 min. H3N2 and H9N2 were minorly affected under $0.1 \mathrm{mg} / \mathrm{mL}$ PoGNP and still exhibited higher cell viability than the control group. PoGNP displayed antiviral activity on various virus strains, which is important for on-the-spot preprocessing of IAV for further analysis. Here, we could conclude that $0.2 \mathrm{mg} / \mathrm{mL}$ PoGNP could attenuate the infectivity of multiple IAV strains.

\section{Intracellular viral RNA quantification}

We had inferred the inactivation mechanism of the virus as the cleavage of disulfide bonds, because the high affinity of the disulfide-gold interaction and abundant presence of disulfide bonds in HA would expedite inhibition by PoGNP. The viral inhibition mechanism of PoGNP was then identified by quantitative analysis of intracellular viral RNA from MDCK cells infected with nanoparticle-treated viruses (Fig. 6). MDCK cells were infected with PoGNP-treated H3N2 virus for $24 \mathrm{~h}$ and the cells were lysed with Qiagen RNeasy mini kit, followed by calculation of $\operatorname{logEID}{ }_{50} / \mathrm{mL}$ values by standard EID curve (Additional file 1: Figure S4). PoGNP-treated H3N2 virus showed lower intracellular viral RNA levels indicating that the amount of IAV in the endosome of MDCK cells was clearly reduced in the nanoparticle-treated samples. Also, the amount of intracellular viral RNA was 


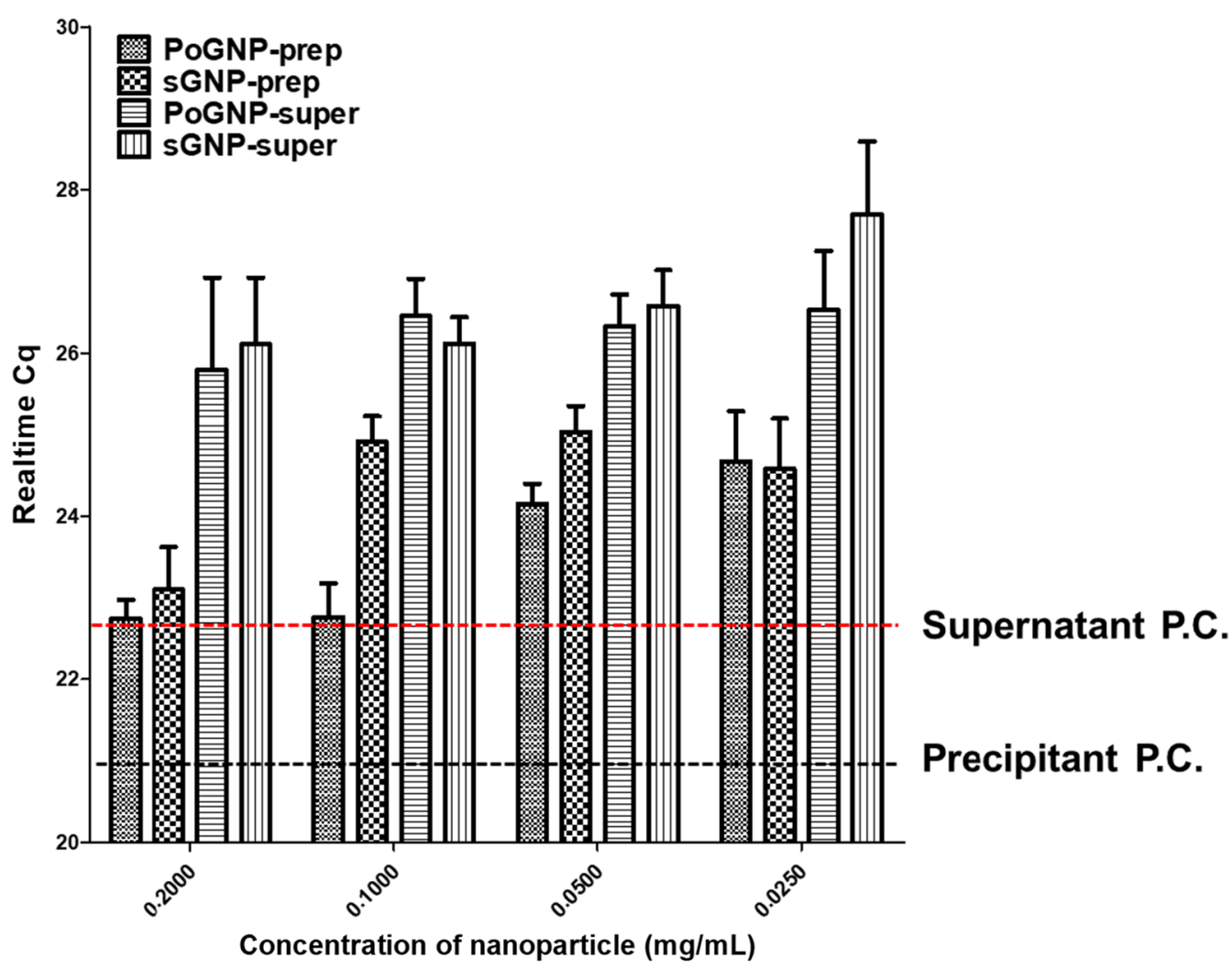

Fig. 3 Real-time RT-PCR data of nanoparticle-treated IAVs after centrifugation. (Red dotted line: supernatant positive control, black dotted line: precipitate positive control, viral titer: $10^{6} \mathrm{EID}_{50} / \mathrm{mL}$ ). PoGNP-Prep, precipitate of PoGNP-treated IAV after centrifugation; sGNP-Prep, precipitate of sNGP-treated IAV after centrifugation; PoGNP-Super, supernatant of PoNGP-treated IAV after centrifugation; sGNP-Super, supernatant of sNGP-treated IAV after centrifugation. PoGNP porous gold nanoparticle, sGNP spherical gold nanoparticle, AgNP silver nanoparticle

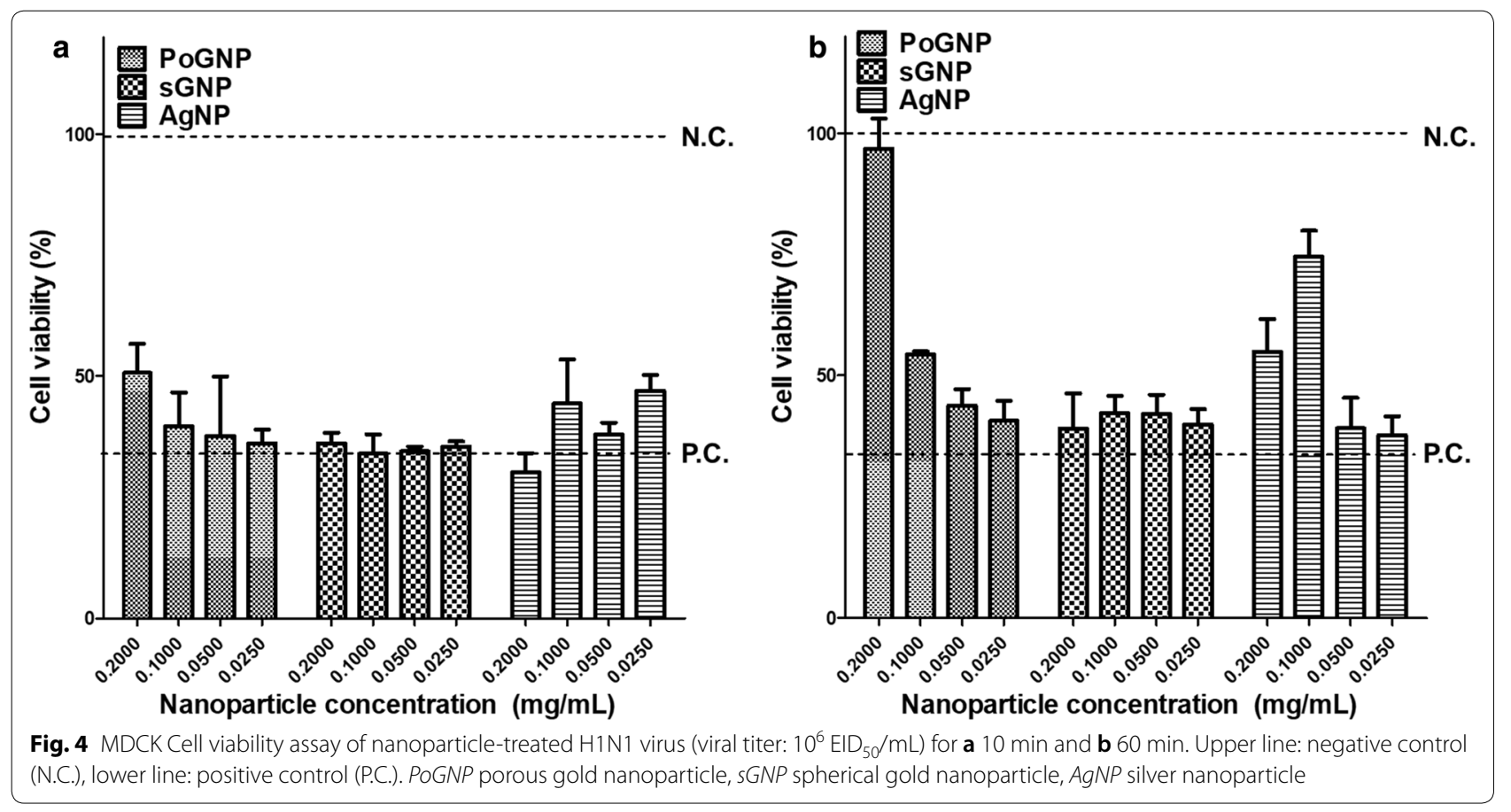



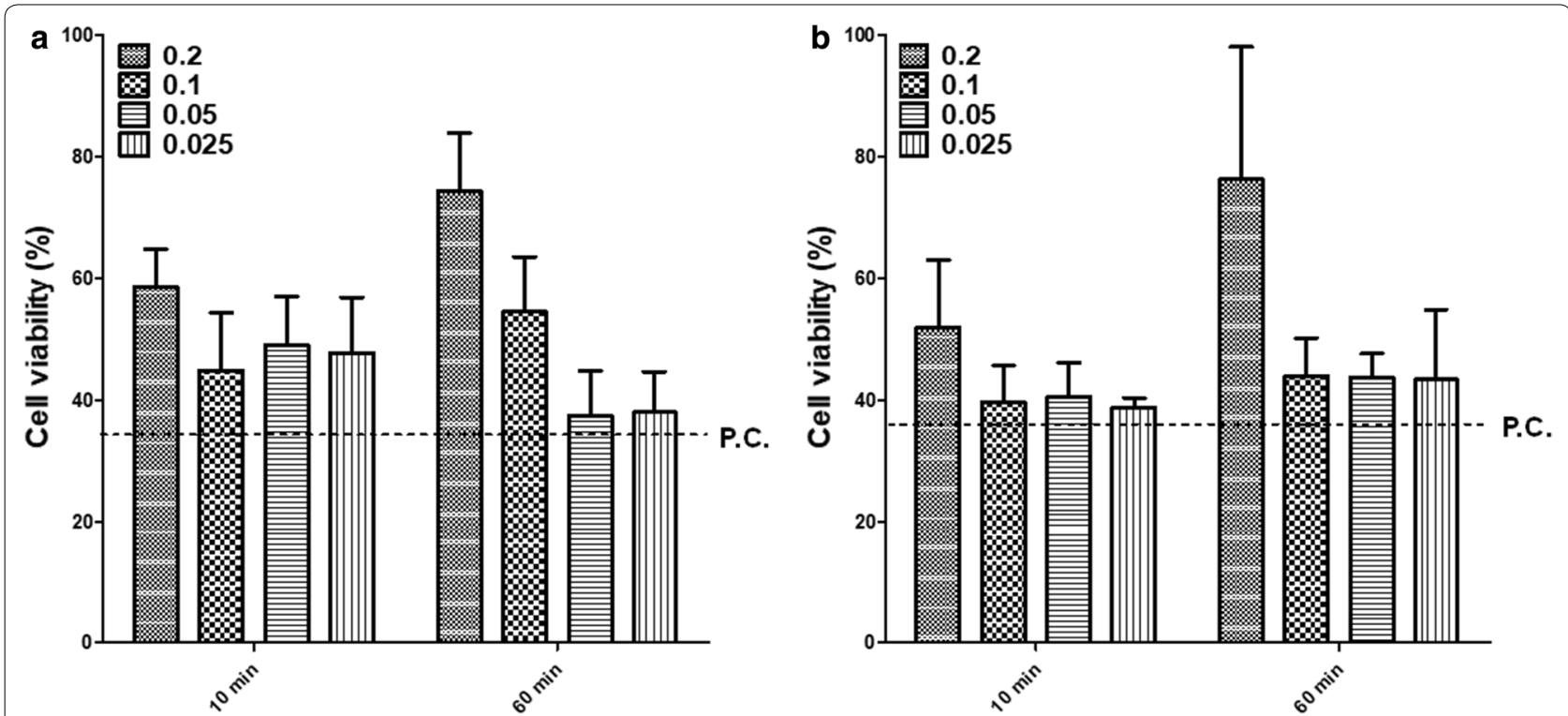

Fig. 5 MDCK cell viability assay of PoGNP treatment for 10 min and 60 min on a H1N1, b H3N2 virus-infected cells. [Viral titer: $10^{6}$ EID $50 / \mathrm{mL}^{2}$ dotted line: positive control (P.C.)]

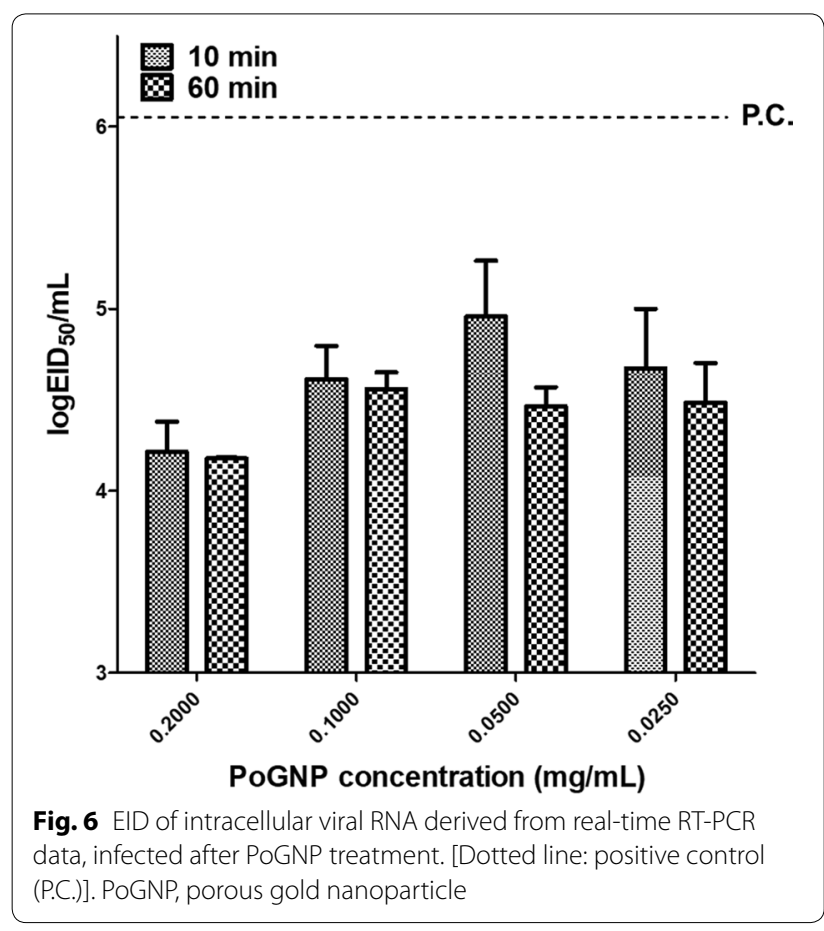

clearly influenced by the exposure time. The gene content level of viral RNA in the host cells was higher for viruses treated for $10 \mathrm{~min}$ compared with $60 \mathrm{~min}$. Intracellular viral RNA quantification data corresponded well with the MDCK cell viability test results, revealing that the antiviral activity of PoGNP was affected by time and concentration, especially $0.2 \mathrm{mg} / \mathrm{mL}$ PoGNP was effective after exposure for $10 \mathrm{~min}$. Furthermore, the result also confirmed that PoGNP blocked viral infection by inhibiting viral entry.

\section{Demonstrating the importance of disulfide bond in viral infection}

We determined that viral infection was suppressed by obstructing viral attachment, therefore we further experimented to prove that the disulfide bonds in HA have important role in viral infection. To support the hypothesis, 5,5'-dithiobis(2-nitrobenzoic acid) (DTNB) reduction assay (Ellman's assay) was proposed to quantify the reduced disulfide bonds in virus hemagglutinin which had been in contact with $0.2 \mathrm{mg} / \mathrm{mL}$ of PoGNP, sGNP and AgNP (Fig. 7). As the higher sulfhydryl group concentration in the virus means the more reduction of disulfide bond has occurred, Ellman's assay was considered as a valid method for proving relationship between viral disulfide bond reduction and its attenuated infectivity. As described in Fig. 7, absorbance at $412 \mathrm{~nm}\left(\mathrm{~A}_{412}\right)$ of influenza virus that was exposed to $0.2 \mathrm{mg} / \mathrm{mL}$ PoGNP showed higher $\mathrm{A}_{412}$ than sGNP and AgNP counterpart at the same concentration, indicating that PoGNP have higher affinity to the disulfide bonds in HA. Despite the size of PoGNP slightly larger than sGNP, PoGNP's higher relative surface area made a big difference in disulfide bond reduction while AgNP still displayed reductive reaction on the bonds in HA. TCEP was chosen as a positive control group of disulfide bond reducing agent since 


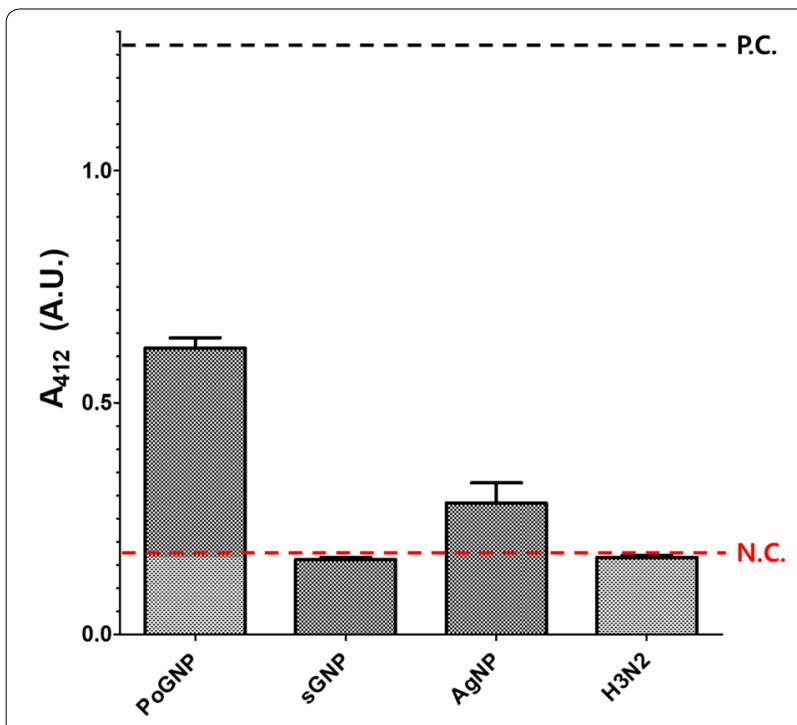

Fig. 7 DTNB reduction assay performed with $10^{6} \mathrm{TCID}_{50} / \mathrm{mL}$ of $\mathrm{H} 3 \mathrm{~N} 2$ that had reacted with $0.2 \mathrm{mg} / \mathrm{mL}$ of various nanoparticles for $60 \mathrm{~min}$. (Black dotted line: positive control, 0.01 M TCEP with virus suspension; Red dotted line: negative control, 1 mM DTNB in 10\% ethanol solution)

TCEP structure do not have any disulfide bond after reduced the $\mathrm{S}-\mathrm{S}$ bond in $\mathrm{HA}$, and thus it has little effect on DTNB reduction after reacting with disulfide bonds in HA.

Moreover, results of the WST-1 assay revealed that TCEP-treated IAVs lost their infectivity similar to PoGNP-treated viruses. Samples treated with under $1 \mathrm{mM}$ TCEP exhibited nearly $60 \%$ cell viability, which was much higher than the $33 \%$ viability of $\mathrm{H} 3 \mathrm{~N} 2$ virusinfected MDCK cells (Additional file 1: Figure S5). On the other hand, $0.01 \mathrm{M}$ TCEP-treated samples displayed lower cell viability compared to other TCEP-treated samples because of the cytotoxicity of TCEP itself [34]. The result suggested that the cleavage of disulfide bond before membrane fusion reduce viral infectivity toward MDCK cells. Likewise, as the viral infectivity of PoGNP-reacted influenza virus was suppressed to the level similar to that of the TCEP interacted one, which derives that PoGNP also cleaves the disulfide bonds in HA as TCEP.

\section{Conclusion}

We demonstrated the antiviral activity of PoGNP in comparison with non-porous gold and silver nanoparticles in this study. Nanoparticle morphology and interaction with IAV was observed by TEM analysis and the interaction between PoGNP and HA was further proven by coprecipitation during centrifugation. Precipitation of PoGNP-treated IAVs showed lower real-time Cq values, indicating that more viruses precipitated with nanoparticles than were free in the supernatant. Furthermore, PoGNP showed more effective inhibition of viral infection compared with the non-porous sGNP and AgNP because of its extensive surface area. We suggested that the viral inhibition mechanism was due to blocking of viral attachment associated with membrane fusion, which ensued from the cleavage of disulfide bonds in HA. The results indicate that the disulfide bonds in HA could be an effective antiviral target, presenting possible development of antiviral vaccines for various IV strains. Likewise, we suggest that PoGNP could be applied to other enveloped viruses that have considerable spike proteins on the surface, such as human immunodeficiency virus or coronavirus, by cleaving disulfide bonds in their spike proteins. In addition, PoGNP has numerous electromagnetic hot spots compared to non-porous gold and silver nanoparticles, and the application of surface enhanced Raman spectroscopy (SERS) should be considered for future analysis. The findings of this study imply that a facile detection of IAV can be achieved by developing PoGNP as a multiplatform for detection and inactivation of the virus.

\section{Methods}

\section{Materials}

Gold (III) chloride trihydrate, silver (I) nitrate, tannic acid, sodium citrate, hydroquinone, polyvinylpyrrolidone (PVP), phosphotungstic acid hydrate (PTA), L-cysteine, monosodium phosphate, disodium phosphate and aniline were purchased from Sigma-Aldrich (St. Louis, USA). Ethanol and $N$-methyl-2-pyrrolidone (NMP) was obtained from Duksan Pure Chemicals Co., Ltd. (Ansan, South Korea). Dulbecco's Modified Eagle Medium (DMEM), Dulbecco's phosphate buffered saline (DPBS, $\mathrm{pH}$ 7.4), and fetal bovine serum (FBS) were purchased from Gibco Laboratories (Gaithersburg, USA). Ellman's reagent [5,5'-dithiobis(2-nitrobenzoic acid), DTNB] was purchased from Thermo Scientific (Waltham, USA). The Ez-cytox cell viability assay kit was purchased from Daeil Lab Service (Seoul, Korea). The RNeasy ${ }^{\circledR}$ mini kit and the QIAamp ${ }^{\circledR}$ viral RNA mini kit were purchased from QIAGEN (Hilden, Germany). A/California/04/2009 (H1N1), A/canine/Korea/GCVP01/2007(H3N2) and A/wild bird feces/Korea/KU-VI135874/2012(H9N2) were prepared.

\section{Synthesis of metallic nanoparticle}

PoGNP was prepared following the surfactant-free emulsion method [29]. Aniline monomer $(0.182 \mathrm{~mL}, 2 \mathrm{mmol})$ was dispersed in $20 \mathrm{~mL}$ of deionized water. Then, $1 \mathrm{~mL}$ of gold (III) chloride solution $(0.1 \mathrm{M})$ was added to construct a polyaniline (PANI)-Au hybrid nanoparticle under emulsification for $30 \mathrm{~min}$ with ultrasonication. The produced PANI-Au nanoparticle was washed 
$3 \times$ by centrifugation. PANI was then removed from the PANI-Au composite by dissolving the composite in NMP. Finally, purified PoGNP was redispersed in DPBS.

AgNP was synthesized following the citrate reduction method [35]. Tannic acid (42 $\mathrm{mg}, 0.025 \mathrm{mmol})$ and sodium citrate $(150 \mathrm{mg}, 0.5 \mathrm{mmol})$ were dissolved in $100 \mathrm{~mL}$ of deionized water, and the solution was heated to $95{ }^{\circ} \mathrm{C}$ with vigorous stirring. Then $1 \mathrm{~mL}$ of silver (I) nitrate solution $(25 \mathrm{mM})$ was quickly injected and reacted for $1 \mathrm{~h}$ at $95^{\circ} \mathrm{C}$.

Non-porous sGNP was obtained following the seedmediated growth method [36]. First, gold nanoparticle (GNP) seed was synthesized using the citrate reduction method. Briefly, $100 \mathrm{~mL}$ of sodium citrate solution $(5 \mathrm{mM})$ was heated to $95^{\circ} \mathrm{C}$ with vigorous stirring. Thereafter, $1 \mathrm{~mL}$ of gold (III) chloride solution $(0.1 \mathrm{M})$ was injected into the sodium citrate solution. After $30 \mathrm{~min}$, a wine-colored GNP seed solution was obtained. Then, $100 \mu \mathrm{L}$ of gold (III) chloride solution $(25 \mathrm{mM})$ was added to GNP seed solution $(0.8 \mu \mathrm{M})$ to give a final volume of $10 \mathrm{~mL}$. Subsequently, $22 \mu \mathrm{L}$ of sodium citrate solution $(30 \mathrm{mM})$ was injected into the seed solution mixture, following the addition of $100 \mu \mathrm{L}$ of hydroquinone solution $(30 \mathrm{mM})$. The mixture was kept at room temperature (RT) for $24 \mathrm{~h}$. PVP solution $(2 \mu \mathrm{g} / \mathrm{mL})$ was added to prevent the aggregation of nanoparticles, followed by centrifugation at $10,000 \mathrm{rpm}$ for $10 \mathrm{~min}$.

Size distribution and zeta potential of each nanoparticle was collected by ELS-Z2000 (Otsuka electronics Co., Ltd., Osaka), and concentration of particles were analyzed through an inductively-coupled plasma optical emission spectrometer (ICP-OES, Perkin Elmer, Waltham).

\section{Binding efficiency between nanoparticle and influenza virus}

$300 \mu \mathrm{L}$ aliquots of $\mathrm{H} 3 \mathrm{~N} 2$ virus suspension were exposed to $2 \times 10^{-1} \mathrm{mg} / \mathrm{mL}$ to $6.25 \times 10^{-3} \mathrm{mg} / \mathrm{mL}$ of nanoparticle (PoGNP and sGNP) solution and incubated at RT for $1 \mathrm{~h}$. Subsequently, the incubated samples were centrifuged at $8000 \mathrm{rpm}$ for $10 \mathrm{~min}$ to separate the virusbound nanoparticles from the supernatant solutions. The supernatants were transferred to other test tubes while the precipitates were dispersed in DPBS. Thereafter, real-time RT-PCR analysis was conducted on the prepared solutions to determine the binding efficiency of the nanoparticles.

\section{Cytotoxicity assay for antiviral activities}

The water-soluble tetrazolium salt-1 (WST-1) assay was performed to determine the cytotoxicity of the nanoparticle-treated IAVs on MDCK cells using the Ez-cytox cell viability assay kit (Daeil Lab Service). Twenty-four hours prior to the infection experiment, $2.0 \times 10^{5}$ of Madin-Darby canine kidney (MDCK) cells were seeded into 96-well plates with $100 \mu \mathrm{L}$ of $10 \%$ fetal bovine serum (FBS) containing DMEM.

In order to evaluate the antiviral activity of the nanoparticles, various nanoparticle concentrations $\left(3.125 \times 10^{-2} \mathrm{mg} / \mathrm{mL}\right.$ to $2 \times 10^{-1} \mathrm{mg} / \mathrm{mL}$ of PoGNP, sGNP, and AgNP) with twofold serial dilutions and $300 \mu \mathrm{L}$ aliquots of IAVs (H1N1, H3N2, and H9N2) were prepared. $75 \mu \mathrm{L}$ of each nanoparticle solution was added to the virus aliquots, for a final nanoparticle concentration of $6.25 \times 10^{-3} \mathrm{mg} / \mathrm{mL}$ to $2 \times 10^{-1} \mathrm{mg} / \mathrm{mL}$. Samples were incubated at RT for $10 \mathrm{~min}$ and $60 \mathrm{~min}$, with vortex mixing every $10 \mathrm{~min}$. In the meantime, the MDCK cells were washed $3 \times$ with $100 \mu \mathrm{L}$ of PBS. Then $100 \mu \mathrm{L}$ aliquots of nanoparticle-treated IAV samples were added to each well and incubated for an additional $1 \mathrm{~h}$. The nanoparticle-treated IAVs were then removed, cells were rinsed once with PBS, and then incubated for an additional $72 \mathrm{~h}$ with $200 \mu \mathrm{L}$ of fresh DMEM.

To determine cell viability, $20 \mu \mathrm{L}$ of Ez-cytox was added to the incubated cells and their optical density (OD) at $450 \mathrm{~nm}$ was measured after $2 \mathrm{~h}$ using the UV-Vis SpectraMax 190 Microplate Reader (Molecular Devices, San Jose, USA).

For intracellular viral RNA quantification, a $24 \mathrm{~h}$ MDCK cell incubation period was followed by the RNeasy $^{\circledR}$ mini kit protocol (QIAGEN) to prepare samples for real-time RT-PCR analysis.

\section{Transmission electron microscopy (TEM) analysis}

$30 \mu \mathrm{L}$ of the nanoparticle and virus suspension mixtures, as previously described in cytotoxicity assay part, were incubated at RT for 10 and $60 \mathrm{~min}$ and then transferred by pipette to carbon-coated copper TEM grids (400 mesh). After $10 \mathrm{~min}$ at RT, the liquid was blotted with filter paper and a droplet of $3 \mathrm{wt} \%$ PTA solution was loaded onto the grid for negative staining. The excess PTA solution was blotted with filter paper after 10-40 s, followed by washing $2 \times$ with a droplet of deionized water, and the grid was dried for $4 \mathrm{~h}$ prior to analysis. TEM images were obtained with a JEM-1011 transmission electron microscope (JEOL Ltd., Tokyo, Japan).

\section{Real-time RT-PCR}

A/canine/Korea/GCVP01/2007(H3N2) virus was serially diluted tenfold $\left(108.25-102.25 \quad \mathrm{EID}_{50} / \mathrm{mL}\right)$. Viral genomic RNA from each dilution was extracted using the QIAamp ${ }^{\circledR}$ viral RNA mini kit (QIAGEN), according to the manufacturer's instructions. Real-time reverse transcription-polymerase chain reaction (RT-PCR) was employed to quantify the viral load in the samples using the QuantiTect Probe RT-PCR Kit (QIAGEN) and the 
LightCycler 96 system (Roche, Basel, Switzerland). The $50 \mu \mathrm{L}$ final reaction volume contained $0.4 \mu \mathrm{M}$ of matrix (M) gene-specific primer (forward: GACCRATCCTGT CACCTCTGAC; reverse: AGGGC ATTYTGGACAAA KC GTCTA) and $0.2 \mu \mathrm{M}$ of specific probe (FAM-TGC AGTCCTCGCTCACTGGGCACG-BHQ-1). The thermal cycling conditions were: reverse transcription at $50{ }^{\circ} \mathrm{C}$ for $30 \mathrm{~min}$, initial denaturation at $95{ }^{\circ} \mathrm{C}$ for $5 \mathrm{~min}$, followed by 40 cycles of $\left[94{ }^{\circ} \mathrm{C}\right.$ for $15 \mathrm{~s}, 60{ }^{\circ} \mathrm{C}$ for $60 \mathrm{~s}$ ] according to the manufacturer's protocol (Roche). The primers targeted the region of the $\mathrm{M}$ gene highly conserved across all IAV strains, as formulated by the CDC (Biosearch Technologies, Inc. http://www.who.int/csr/ resources/publications/swineflu/CDCrealtimeRTPC Rprotocol_20090428.pdf). A standard curve was generated with EID values and copy numbers. The amount of viral RNA in nanoparticle-treated samples (in $\operatorname{logEID}_{50} /$ $\mathrm{mL}$ ) was calculated from the standard curve generated by real-time RT-PCR data using canine H3N2 virus (Additional file 1: Figure S4).

\section{Ellman's assay}

$10 \mathrm{mM}$ of DTNB in $10 \%$ ethanol solution and $0.1 \mathrm{M}$ sodium phosphate buffer $\mathrm{pH} 7.4$ was prepared. Then $50 \mu \mathrm{L}$ of $0.2 \mathrm{mg} / \mathrm{mL}$ PoGNP, sGNP and AgNP aliquot was mixed with $50 \mu \mathrm{L}$ of $\mathrm{H} 3 \mathrm{~N} 2$ virus and left for $60 \mathrm{~min}$ at RT. $100 \mu \mathrm{L}$ of $1 \mathrm{mM}$ DTNB solution was set as a negative control for the signal, and $100 \mu \mathrm{L}$ of H3N2 virus suspension reacted with $10 \mathrm{mM}$ TCEP for $60 \mathrm{~min}$ was prepared as a positive control. Subsequently, $20 \mu \mathrm{L}$ of $10 \mathrm{mM}$ DTNB solution was added to the mixture. Centrifugation of reactant was followed to remove nanoparticles in the mixture. Next, absorbance at $412 \mathrm{~nm}\left(\mathrm{~A}_{412}\right)$ was observed using the UV-Vis SpectraMax 190 Microplate Reader (Molecular Devices, San Jose, USA).

\section{Supplementary information}

Supplementary information accompanies this paper at https://doi. org/10.1186/s12951-020-00611-8.

Additional file 1: Figure S1. Size distribution plot of (A) PoGNP (B) sGNP (C) AgNP; Polydispersity index (PDI) of each nanoparticle was 0.058, 0.032 and 0.048 , respectively. Figure S2. MDCK cell viability after treatment with (A) PoGNP (B) sGNP and (C) AgNP at various nanoparticle concentrations. Figure S3. MDCK cell viability assay of PoGNP treatment for $10 \mathrm{~min}$ and 60 min on H9N2 virus infected cell. (viral titer: $106 \mathrm{EID50} / \mathrm{mL}$, dotted line: positive control (P.C.)). Figure S4. Standard curve of EID value derived by real-time RT-PCR. Figure S5. MDCK cell viability after infection with TECPtreated H3N2 virus. Upper line: negative control (N.C.), lower line: positive control (P.C.). (viral titer: $10^{6} \mathrm{EID} / \mathrm{mL}$ )

\section{Authors' contributions}

JK and MY have equally contributed on this article. JK and MY designed and drafted the manuscript. JK and TL synthesized and characterized PoGNP.

$J Y$ and HK conducted detailed experiment. MY, AK and WN supported cell preparation and virus collection. JL, GP and CW assisted in data analysis. DS and SH supervised entire experiment. All authors read and approved the manuscript.

\section{Funding}

This research was supported by the Bio \& Medical Technology Development Program of the National Research Foundation (NRF) funded by the Korean government (MSIT) (No. 2018M3A9H4056340). This work was supported by the National Research Foundation of Korea (NRF) grant funded by the Korean government (MEST) (NRF-2016R1A6A3A11933558 and NRF-2019R111A1A01057005).

\section{Availability of data and materials}

All data generated or analyzed during this study are included in this published article and its supplementary information files.

\section{Ethics approval and consent to participate}

Not applicable.

\section{Consent for publication}

Not applicable.

\section{Competing interests}

The authors declare no competing financial interest.

\section{Author details}

${ }^{1}$ Department of Chemical and Biomolecular Engineering, Yonsei University, Yonsei-ro 50, Seoul 120-749, Republic of Korea. ${ }^{2}$ Department of Pharmacy, Korea University College of Pharmacy, Sejong-ro 2511, Sejong 30019, Republic of Korea. ${ }^{3}$ Department of Nano Manufacturing Technology, Korea Institute of Machinery and Materials (KIMM), 156 Gajeongbuk-Ro, Yuseong-Gu, Daejeon 34103, Republic of Korea. ${ }^{4}$ College of Veterinary Medicine, Chonnam National University, Yongbong-ro 77, Buk-Gu, Gwangju, South Korea.

Received: 10 January 2020 Accepted: 16 March 2020

Published online: 24 March 2020

\section{References}

1. Mahony JB. Detection of respiratory viruses by molecular methods. Clin Microbiol Rev. 2008;21:716-47.

2. Thompson WW, Shay DK, Weintraub E, Brammer L, Bridges CB, Cox NJ, Fukuda K. Influenza-associated hospitalizations in the United States. JAMA. 2004;292:1333-40.

3. Simonsen L, Fukuda K, Schonberger LB, Cox NJ. The impact of influenza epidemics on hospitalizations. J Infect Dis. 2000:181:831-7.

4. Cox NJ, Subbarao K. Global epidemiology of influenza: past and present. Annu Rev Med. 2000;51:407-21.

5. Poland GA, Jacobson RM, Ovsyannikova IG. Influenza virus resistance to antiviral agents: a plea for rational use. Clin Infect Dis. 2009;48:1254-6.

6. Centers for Disease C, Prevention. Update: influenza activity-United States. Morb Mortal Wkly Rep. 2008;57:1329-32.

7. Thompson Cl, Barclay WS, Zambon MC. Changes in in vitro susceptibility of influenza A H3N2 viruses to a neuraminidase inhibitor drug during evolution in the human host. J Antimicrob Chemother. 2004;53:759-65.

8. Samson M, Pizzorno A, Abed Y, Boivin G. Influenza virus resistance to neuraminidase inhibitors. Antiviral Res. 2013:98:174-85.

9. Gubareva LV. Molecular mechanisms of influenza virus resistance to neuraminidase inhibitors. Virus Res. 2004;103:199-203.

10. Floyd DL, Ragains JR, Skehel JJ, Harrison SC, van Oijen AM. Single-particle kinetics of influenza virus membrane fusion. Proc Natl Acad Sci USA. 2008;105:15382-7.

11. Carr CM, Kim PS. A spring-loaded mechanism for the conformational change of influenza hemagglutinin. Cell. 1993;73:823-32.

12. Kim HO, Na W, Yeom M, Choi J, Kim J, Lim JW, Yun D, Chun H, Park G, Park C, et al. Host cell mimic polymersomes for rapid detection of highly pathogenic influenza virus via a viral fusion and cell entry mechanism. Adv Funct Mater. 2018;28:1800960.

13. Fontana J, Steven AC. Influenza virus-mediated membrane fusion: structural insights from electron microscopy. Arch Biochem Biophys. 2015:581:86-97. 
14. Skehel JJ, Bayley PM, Brown EB, Martin SR, Waterfield MD, White JM, Wilson IA, Wiley DC. Changes in the conformation of influenza-virus hemagglutinin at the Ph optimum of virus-mediated membrane-fusion. Proc Natl Acad Sci USA. 1982;79:968-72.

15. Chen J, Lee KH, Steinhauer DA, Stevens DJ, Skehel JJ, Wiley DC. Structure of the hemagglutinin precursor cleavage site, a determinant of influenza pathogenicity and the origin of the labile conformation. Cell. 1998;95:409-17.

16. Mehrbod P, Motamed N, Tabatabaian M, Soleimani ER, Amini E, Shahidi M, Kheiri MT. In vitro antiviral effect of "Nanosilver" on influenza virus. Daru. 2009;17:88-93.

17. Xiang D, Zheng Y, Duan W, Li X, Yin J, Shigdar S, O'Connor ML, Marappan M, Zhao X, Miao Y, et al. Inhibition of A/Human/Hubei/3/2005 (H3N2) influenza virus infection by silver nanoparticles in vitro and in vivo. Int J Nanomed. 2013;8:4103-13.

18. Elechiguerra JL, Burt JL, Morones JR, Camacho-Bragado A, Gao X, Lara HH, Yacaman MJ. Interaction of silver nanoparticles with HIV-1. J Nanobiotechnol. 2005;3:6.

19. Orlowski P, Tomaszewska E, Gniadek M, Baska P, Nowakowska J, Sokolowska J, Nowak Z, Donten M, Celichowski G, Grobelny J, Krzyzowska M. Tannic acid modified silver nanoparticles show antiviral activity in herpes simplex virus type 2 infection. PLoS ONE. 2014;9:e104113.

20. Mori Y, Ono T, Miyahira Y, Nguyen VQ, Matsui T, Ishihara M. Antiviral activity of silver nanoparticle/chitosan composites against H1N1 influenza A virus. Nanoscale Res Lett. 2013;8:93.

21. Yang XX, Li CM, Huang CZ. Curcumin modified silver nanoparticles for highly efficient inhibition of respiratory syncytial virus infection. Nanoscale. 2016;8:3040-8.

22. Lara HH, Ayala-Nunez NV, Ixtepan-Turrent L, Rodriguez-Padilla C. Mode of antiviral action of silver nanoparticles against HIV-1. J Nanobiotechnol. 2010;8:1.

23. Lara HH, Ixtepan-Turrent L, Garza-Trevino EN, Rodriguez-Padilla C. PVPcoated silver nanoparticles block the transmission of cell-free and cellassociated HIV-1 in human cervical culture. J Nanobiotechnol. 2010;8:15.

24. Wei JH, Zheng LT, Lv X, Bi YH, Chen WW, Zhang W, Shi Y, Zhao L, Sun XM, Wang $F$, et al. Analysis of influenza virus receptor specificity using glycanfunctionalized gold nanoparticles. ACS Nano. 2014;8:4600-7.

25. Papp I, Sieben C, Ludwig K, Roskamp M, Bottcher C, Schlecht S, Herrmann A, Haag R. Inhibition of influenza virus infection by multivalent sialic-acidfunctionalized gold nanoparticles. Small. 2010;6:2900-6.
26. Bowman MC, Ballard TE, Ackerson CJ, Feldheim DL, Margolis DM, Melander C. Inhibition of HIV fusion with multivalent gold nanoparticles. J Am Chem Soc. 2008;130:6896-7.

27. Sametband M, Shukla S, Meningher T, Hirsh S, Mendelson E, Sarid R, Gedanken A, Mandelboim M. Effective multi-strain inhibition of influenza virus by anionic gold nanoparticles. Medchemcomm. 2011;2:421-3.

28. Haider A, Das S, Ojha D, Chattopadhyay D, Mukherjee A. Highly monodispersed gold nanoparticles synthesis and inhibition of herpes simplex virus infections. Mater Sci Eng C-Mater Biol Appl. 2018;89:413-21.

29. Bang D, Lee T, Choi J, Park Y, Kim E, Huh YM, Haam S. A multistep photothermic-driven drug release system using wire-framed Au nanobundles. Adv Healthc Mater. 2015;4:255-63.

30. Lee T, Bang D, Chang YW, Choi Y, Park KY, Oh A, Han S, Kim SH, Lee K, Suh JS, et al. Cancer theranosis using mono-disperse, mesoporous gold nanoparticles obtained via a robust, high-yield synthetic methodology. RSC Adv. 2016;6:13554-61.

31. Taylor AR, Sharp DG, McLean IW Jr, Beard D, Beard JW, Dingle JH, Feller AE. Purification and character of the swine influenza virus. Science. 1943;98:587-9.

32. Arora DJ, Tremblay P, Bourgault R, Boileau S. Concentration and purification of influenza virus from allantoic fluid. Anal Biochem. 1985;144:189-92.

33. Kirkpatrick E, Qiu XT, Wilson PC, Bahl J, Krammer F. The influenza virus hemagglutinin head evolves faster than the stalk domain. Sci Rep. 2018:8:1-14

34. Chen GL, Zhang SB, Jin YX, Wu Y, Liu L, Qian HF, Fu ZW. TPP and TCEP induce oxidative stress and alter steroidogenesis in TM3 Leydig cells. Reprod Toxicol. 2015;57:100-10.

35. Bastus NG, Merkoci F, Piella J, Puntes V. Synthesis of highly monodisperse citrate-stabilized silver nanoparticles of up to $200 \mathrm{~nm}$ : kinetic control and catalytic properties. Chem Mater. 2014;26:2836-46.

36. Perrault SD, Chan WC. Synthesis and surface modification of highly monodispersed, spherical gold nanoparticles of 50-200 nm. J Am Chem Soc. 2009;131:17042-3.

\section{Publisher's Note}

Springer Nature remains neutral with regard to jurisdictional claims in published maps and institutional affiliations.
Ready to submit your research? Choose BMC and benefit from:

- fast, convenient online submission

- thorough peer review by experienced researchers in your field

- rapid publication on acceptance

- support for research data, including large and complex data types

- gold Open Access which fosters wider collaboration and increased citations

- maximum visibility for your research: over $100 \mathrm{M}$ website views per year

At BMC, research is always in progress.

Learn more biomedcentral.com/submissions 